\title{
Biocontrol of common carp in Australia poses risks to biosecurity
}

To the Editor - The Australian government is considering employing the koi herpesvirus (KHV) for biocontrol of invasive common carp (Cyprinus carpio) in the Murray-Darling river system of southeast Australia in $2018^{1,2}$. KHV is on the World Organisation of Animal Health (OIE) list of notifiable diseases ${ }^{3}$, yet the biocontrol programme has been framed as a safe and manageable proposition ${ }^{1,2}$. Previous reports highlight that viruses have been successfully employed in the biocontrol of terrestrial vertebrates ${ }^{1}$, including cats on Marion Island, and feral rabbits in Australia and New Zealand. However, compared with the biocontrol of terrestrial vertebrates, the biocontrol of large, highly fecund aquatic animals such as carp adds novel risks.

First, host-range evolution of fish herpesviruses has been complex with periods of co-diversification punctuated by host switching events ${ }^{4,5}$. The planned release will result in the propagation of an unprecedented number of viral particles in the environment: estimated to be as many as $2 \times 10^{23}$. Negative results from (relatively small-scale) infection experiments with $\mathrm{KHV}$ and native fish species conducted in the laboratory cannot rule out the possibility of cross infection; the population size in the wild will grant the virus an enormous evolutionary potential, and it will come into contact with a vast number of host individuals of different species, including individuals with compromised immunity. Given our phylogenetic understanding of herpesviruses (and the impossibility of proving a negative), host-switching cannot be ruled out ${ }^{6}$.

Second, KHV has rapidly spread across continents, and it has been documented in 33 countries worldwide since its initial outbreak in $1998^{3}$. Common carp is the most farmed fish in aquaculture with $>26$ million metric tonnes produced in $2015^{7}$, and it is an important food fish in lower- and middle-income countries. The large-scale release of a notifiable disease for biocontrol constitutes a serious risk to global food security.

Third, KHV biocontrol in Australia aims to clear carp from a river catchment of approximately $1,000,000 \mathrm{~km}^{2}$, in which the invader accounts for up to $90 \%$ of the total fish biomass ${ }^{1}$. In the aftermath of KHV release, millions of tonnes of fish will be decomposing in the Australian rivers, resulting in significant declines in dissolved oxygen, eutrophication, algae blooms, as well as spikes in ammonia and bacteria. We fear this could lead to catastrophic ecosystem crashes, which, given the importance of the Murray-Darling Basin for the country's water supply, may also pose a risk to human health.

Finally, common carp is exceptionally fecund; a single female can produce over 10 million eggs per year ${ }^{9}$. Its recruitment rate is several orders of magnitude higher than that of rabbits or cats, which ensures that carp populations can rapidly recover after a population $\mathrm{crash}^{10}$, rendering the long-term success of a carp biocontrol programme unlikely.

Invasive species pose a significant threat to Australian biodiversity, but the proposed biocontrol of common carp with KHV is an irreversible, high-risk proposal. We fear serious ecological, environmental and economic ramifications, whilst its long-term objective to control carp is at best uncertain. $\square$

References

1. Di Giallonardo, F. \& Holmes, E. C. PLoS Pathog. 11, e1004865 (2015)

2. McColl, K., Cooke, B. \& Sunarto, A. Biol. Control 72, 109-117 (2014)

3. Global Invasive Species Database. Species profile: Cyprinus carpio (Invasive Species Specialist Group, accessed 4 October 2010); http://go.nature.com/2iVrOGD

4. McGeoch, D. J., Cook, S., Dolan, A., Jamieson, F. E. \& Telford, E. A. J. Mol. Biol. 247, 443-458 (1995).

5. Waltzek, T. B. et al. Dis. Aquat. Organ. 84, 179-194 (2009).

6. Parrish, C. R. et al. Microbiol. Mol. Biol. Rev. 72, 457-470 (2008).

7. Tveterås, R. Global finfish production review: Gradual growth. Global Aquaculture Advocate (11 January 2016); http://go.nature.com/2jANh8O

8. Thomas, J. F. Water and the Australian Economy (Australian Academy of Technological Sciences and Engineering, 1999).

9. Linhart, O., Kudo, S., Billard, R., Slechta, V. \& Mikodina, E. V. Aquaculture 129, 75-93 (1995).

10. Weber, M. J., Hennen, M. J., Brown, M. L., Lucchesi, D. O. \& St. Sauver, T. R. Fish. Res. 179, 168-178 (2016).

Competing interests

The authors declare no competing financial interests.

Jackie Lighten and Cock van Oosterhout School of Environmental Sciences, University of East Anglia, Norwich Research Park, NR4 7TJ, UK.

e-mail: C.Van-Oosterhout@uea.ac.uk; jackielighten@gmail.com 